\title{
Assessment of Economic Value of Ecosystem Service by Using InVEST Model in South Korea
}

\author{
Choi Ji Young and Lee Sang Don
}

\begin{abstract}
This study aims to estimate the economic value of natural assets through carbon fixation estimation of ecosystem services in Korea. Based on InVEST model, this study evaluated the amount of carbon fixation and economic values of carbon fixation in Korea for a period spanning 1980-2000.

As a result, Economic values assessed by applying carbon transaction prices and Korea's carbon trade discount. Between 1980 and 1990, the economic value of the ecosystem service lost in Korea was $268,380,000$ dollars and the decrease of the amount of carbon fixation by $25,770,000$ tons between 1990 and 2000 corresponded to the economic loss of $268,380,000$ dollars.

Therefore, this research should be utilized in the process of the national development policies for the sustainable development and biodiversity maintenance. Also, It can be regarded as the support to make a development decision of policies through quantification the assessment results and estimation the economic values of ecosystems.
\end{abstract}

Index Terms-Biodiversity, ecosystem services, InVEST model, economic value assessment.

\section{INTRODUCTION}

The Convention on Biological Diversity came into effect in 1998 for the conservation of biodiversity, the sustainable use of its components, and the fair and equitable sharing of benefits arising from genetic resources [1]. Since biodiversity, providing not only immediately usable natural resources but also ecosystem service, is the basic element of ecosystems [2], [3], it is considered as a critical factor when national and local development policies are established in many countries [4]-[7].

Accordingly, studies have been conducted on the method of assessing the values of ecosystem service provided by ecosystems. Although uncertainty is high in an ecosystem because the long-term effects in an ecosystem are difficult to predict, ecological economics has come to the fore as a method of quantitatively assessing the values of ecosystems to establish objective policies for sustainable use of irreplaceable natural resources [8]-[10].

With regard to the international trend of the ecosystem service study, the Intergovernmental Panel on Climate Change (IPCC) requires time-series analysis data of carbon storage depending on the change of the land use, and mentions a carbon estimation method that is spatially specific

Manuscript received June 9, 2017; revised October 12, 2017.

Choi Ji Young is with the Department of Environmental Science and Engineering, Ewha Womans University, Seoul, 120-750, Korea (e-mail: 01052201106@hanmail.net).

Lee Sang Don was with the Department of Environmental Science and Engineering, Ewha Womans University, Seoul, 120-750, Korea (e-mail: 1sd@ewha.ac.kr).
[11]. Some countries in the world perform economic assessment of carbon fixation as an ecosystem service and apply the data obtained from the quantification of ecosystem service to policy-making. With regard to the study of ecosystem service in Korea, qualitative assessment is performed about the quality of habitats in particular regions under development [12], [13]. The ecosystem service study in Korea was started lately in comparison with other countries [14]-[17].

The present study was conducted according to the need for quantitative assessment of ecosystem services to estimate the economic values of ecosystems by using the InVEST model and to provide fundamental data for the policy-making process about Korea's territory for the conservation of biodiversity in Korea.

\section{MAterials AND MethodS}

\section{A. Scope of Study}

The spatial range is South Korea (Fig. 1). From 1970 to 1980 , Korea had the policy management of the national territory, focusing on economic growth and efficiency for economic growth. This resulted in damage to the ecological system and landscape [4]. It also led to the decline of the ecosystem, biodiversity and the deterioration of the quality of life.

It is continuously mentioned on the need for environmental preservation, and the Ministry of Environment is implementing a policy of sustainable development [12]. And In order to recognize the threat of biodiversity, this study site was chosen as Korea choose because there is currently lack of quantitative evaluation of the degraded ecosystem in Korea. The time range is 1980-2000year in order to determine the economic value changes.

\section{B. Research Methods}

InVEST model is developed by Standford University jointed National Capital Project and WWF to identify between the natural assets of ecosystem and the economic relations. Based on result of ecosystem services assessment, policy-makers and stakeholders should set environmental management goals and create scenario in order to achieve the goals [18], [19].

The InVEST Version 3.3.3 Carbon model can present future changes as well as current values and analyze the changes and trends of ecosystem services based on a variety of spatio-time data.

Therefore based on the 1980-2000 Land-use map and 4 coefficient of carbon pool, it was calculated estimation of Carbon Fixation and assessment of economic values. 




Fig. 1. Study area.

\section{InVEST Carbon Model}

Raster data file set drawn from Land-use Map and Carbon pool table to represent each of the land-use map classes are required for modeling by using Arc GIS Map 10.5.

Also another input data is the table of carbon pools (aboveground mass, belowground mass, soil, dead mass) (Fig. 2). This value was compiled from evaluation of published scientific literature on carbon storage to land-use classes and was obtained through the IPCC (Intergovernmental Panel on Climate Change) and [8].

And finally, the carbon prices applied to the analysis were obtained from the 2012-2015 EEX (European Energy Exchange) data which was adopted by the Kyoto protocol [8], and the carbon discount rate was applied to Korea's carbon discount rate of $5 \%$ by manual of the Korea Automobile Standard Association [11], [20].

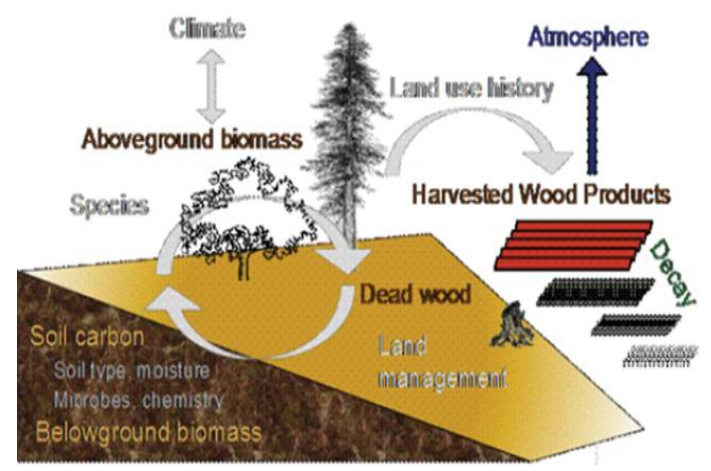

Fig. 2. InVEST carbon model [21].

\section{RESUlTS AND DisCUSSION}

\section{A. Estimation of Carbon Fixation in Respective Periods}

The amount of carbon fixation was decreased over time. Fig. 3 shows that the color was darkened due to the reduction of carbon fixation. Table I and Fig. 4 show the amount of carbon fixation in Korea for respective periods. The amount of carbon fixation was decreased by $9,570,000$ tons between 1980 and 1990. The carbon fixation was decreased more drastically between 1990 and 2000 by $25,770,000$ tons. The total reduction of the carbon fixation between 1980 and 2000 was estimated to be $35,420,000$ tons. Comparison of the data with the ground coverage change pattern in the report published by the Ministry of Environment in 2014 verified the causes for the reduction of the carbon fixation. In the period, the ratios of mountainous regions and grasslands, having high fixation amount, were decreased in the period, while the ratios of urban regions and development regions, having low fixation amount, were increased.

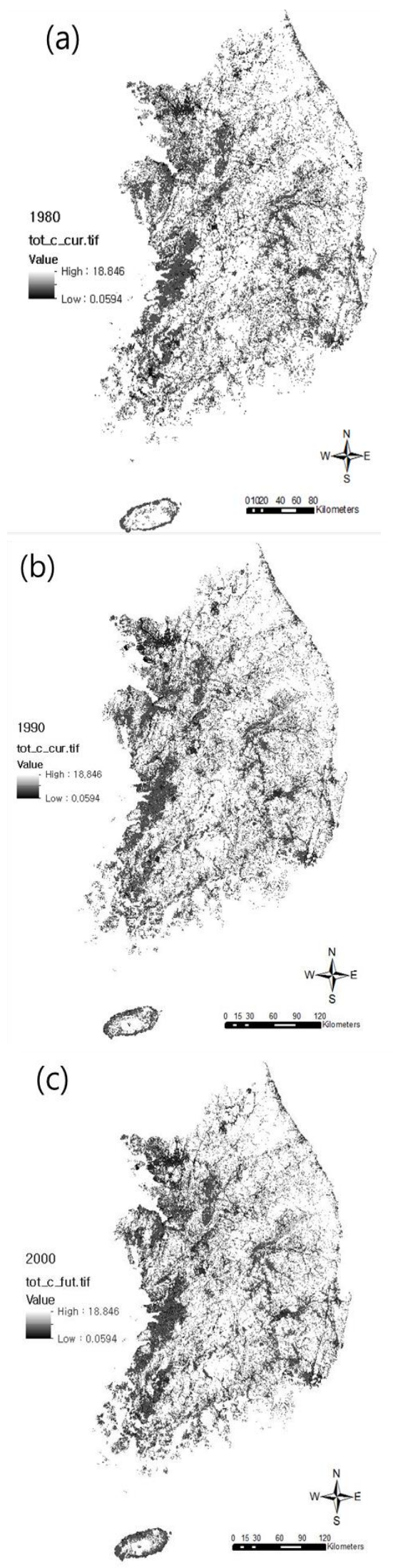

Fig. 3. Map of a mount of Carbon fixation by InVEST in Korea (a) In 1980year, (b) In 1990year and (c) In 2000year. 
TABLE I: ESTIMATION OF CARBON STORAGE IN 1980-2000 YEAR

\begin{tabular}{cccc}
\hline \hline Year & 1980 & 1990 & 2000 \\
\hline $\begin{array}{c}\text { Amount of } \\
\text { carbon } \\
\text { fixation }\end{array}$ & $1,544,152,248.58$ & $1,534,375,694.07$ & $1,508,229,326.73$ \\
$(\mathrm{Mg}$ of $\mathrm{C})$ & & & \\
\hline \hline
\end{tabular}

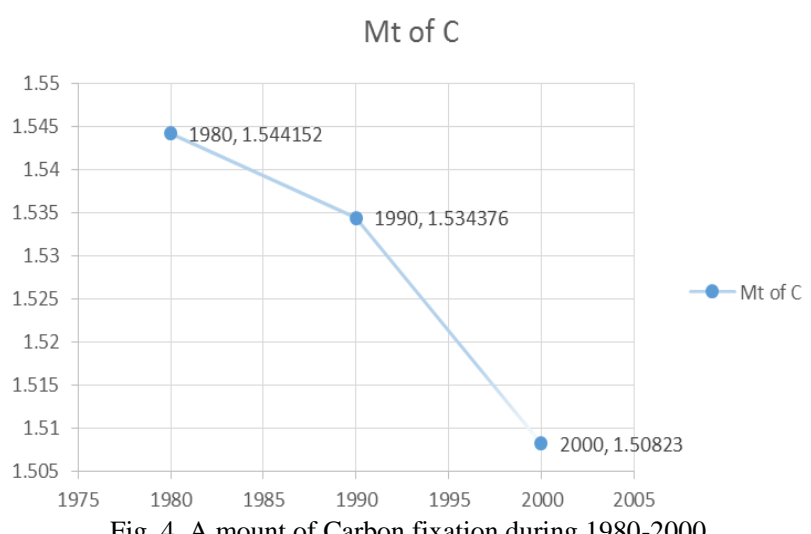

Fig. 4. A mount of Carbon fixation during 1980-2000.

\section{B. Assessment of Economic Values of Carbon Fixation in Respective Periods}

The amount of carbon fixation was estimated by using the InVEST carbon model to assess the economic values of carbon fixation. The carbon prices applied to the analysis were obtained from the European Energy Exchange (EEX) data, and the minimum, average, and maximum prices were 3.4, 7.6, and 11.9 dollars, respectively. Table II shows the economic values assessed according to the variation of the amount of carbon fixation in each period. As the amount of carbon fixation was decreased by $9,570,000$ tons between 1980 and 1990, the economic value of the ecosystem service lost in Korea in the period was $268,380,000$ dollars. The decrease of the amount of carbon fixation by $25,770,000$ tons between 1990 and 2000 corresponded to the economic loss of $71,050,000$ dollars in the ecosystem service in Korea. The amount of the carbon fixation decrease during the two decades from 1980 to 2000 (35,420,000 tons) was estimated to the loss of 78,790,000 dollars in the ecosystem service value.

TABLE II: ESTIMATION OF ECONOMIC LOSS IN EACH YEAR

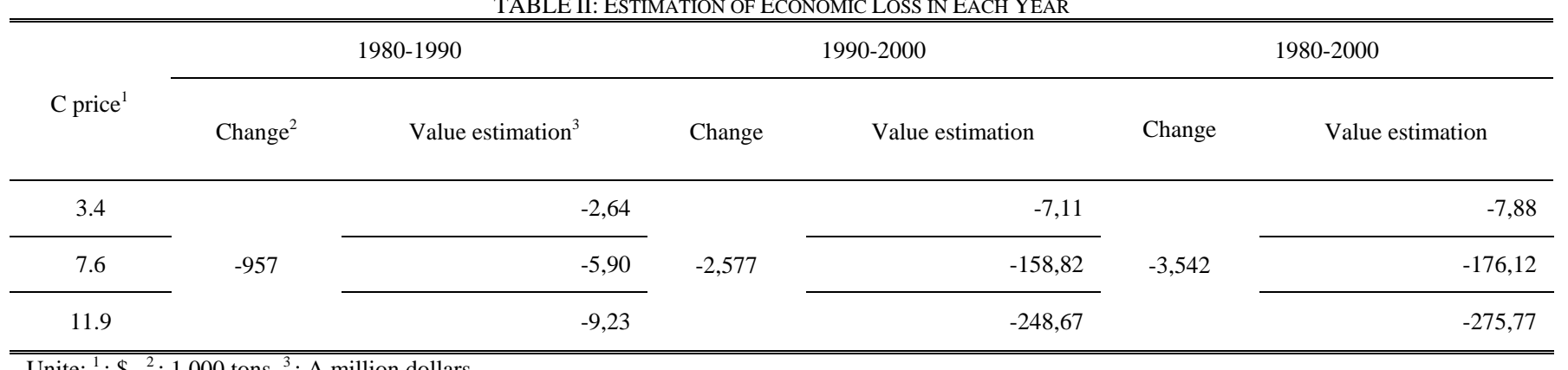

Unite: ${ }^{1}: \$,{ }^{2}: 1,000$ tons $,{ }^{3}:$ A million dollars

Despite the absence of a previous analytical study of ecosystem service using the InVEST Carbon model in a national scale, the reduction of the carbon fixation and the ecosystem service from 1980 and 2000 was quantitatively assessed and the economic loss was estimated to be $78,790,000$ dollars. This indicated the ecosystem service may be assessed in a national scale. Currently, the fundamental data about Korea's ecosystem services are unavailable. However, if the fundamental data about ecosystem services in a national scale are used, more appropriate assessment may be performed with respect to Korea as well as the regions for biodiversity conservation. In addition, since a quantification study on ecosystems is required, the present study provided a possible ecosystem value quantification methodology for each scenario. Fundamental data for policy-making processes for national territory management may be provided through the quantitative assessment of ecosystems, enabling assessment of ecosystems and conversion of the ecosystem services into economic value. Therefore, the methodology of the present study may be used to motivate stakeholders and policy-makers to conserve biodiversity and manage natural resources when they have to make decisions between development and conservation. When legal basis for ecosystem service assessment is prepared in the future, the assessment of ecosystem service may be applied to the decision-making processes for policies and projects in the stage of environmental impact assessment to accomplish sustainable development.

\section{CONCLUSION}

This study showed the economic value of ecosystem services in Korea. Using the InVEST model, this study evaluated the amount of carbon fixation and economic values of carbon fixation in Korea.

It presented the advantage of providing quantitative value to decision makers relatively quickly and easily through evaluation of ecosystem services based on land cover. Also, this study showed a possible analysis of ecosystem service in a national scale and methodology for each scenario using the InVEST Carbon model.

Additionally, for advancing the accuracy of the model, suitable input data in Korea is required. For the more accurate results, after selecting a specific study area, it is needed to obtain input data through the survey with the experts of the area. Applying with the InVEST Carbon modeling based on a Delphi method, it is assumed that carbon fixing assessment and economic evaluation are available more accurately.

\section{APPENDIX}

This work was supported by a grant from the National Institute of Biological Resources (NIBR), funded by the Ministry of Environment (MOE) of the Republic of Korea (NIBR201722201). 


\section{REFERENCES}

[1] P. T. Linda and L. Mark, "The impact of land use change for greenhouse gas inventories and state-level climate mediation policy: A GIS methodology applied to Connecticut," Journal of Environmental Protection, no. 4, pp. 1572-1587, 2014.

[2] J. Fischer et al., "Biodiversity, ecosystem function, and resilience: ten guiding principles for commodity production landscapes," Frontiers in Ecology and the Environment, vol. 4, no. 2, pp. 80-86, 2006.

[3] I. R. Geijzendorffer and P. K. Roche, "Can biodiversity monitoring schemes provide indicators for ecosystem services?" Ecological Indicators, vol. 33, pp. 148-157, 2013.

[4] Korea Environment Institute, "A study on strategic environmental assessment guideline for site selection of offshore wind farm project," 2015 .

[5] R. Costanza et al., "The value of the world's ecosystem services and natural capital," Ecological economics, vol. 25, no. 1, pp. 3-16, 1998.

[6] R. S. Groot et al., "A typology for the classification, description and valuation of ecosystem functions, goods and services," Ecological Economics, vol. 41, no. 3, pp. 393-408, 2002.

[7] MA(Millennium Ecosystem Assessment), "Ecosystems and Biodiversity: Ecological and economic foundations," UNEP, 2005.

[8] Korea Environment Institute, "Development of decision supporting framework to enhance natural capital sustainability: Focusing on ecosystem service analysis," 2015.

[9] N. Lienhoop and F. Messner, "The economic value of allocating water to post-mining lake in east Germany," Wat Res, vol. 23, no. 5, pp. 965-980, 2009.

[10] T. T. Pham et al., "Payments for forest environmental services in Vietnam: from policy to practice," Occasional paper 93, Bogor, Indonesia, 2013.

[11] IPCC, Climate Change 2001: the Scientific Basis. Third Assessment Report of the Intergovernmental Panel on Climate Change, Cambridge University Press, New York, p. 365, 2001.

[12] I. Kong and D. Lee, "Establishment of priority forest areas based on hydrological ecosystem services in Northern Vietnam," Journal of the
Korea Society of Environmental Restoration Technology, vol. 17, no. 5, pp. 29-41, 2014.

[13] D. K. Lee, M. K. Lee, and T. Y. Jung, "Biodiversity, economy," Bomoondang: Seoul, 2014, pp. 176-202.

[14] N. K. Bhagabati et al., "Ecosystem services reinforce Sumatran tiger conservation in land use plans," Biological Conservation, vol. 169, pp. 147-156, 2014.

[15] T. Chiramba et al., "Payment for forest ecosystem services (PFES): Pilot implementation in Lam Dong Province, Vietnam," presented at UN Water. International Conference, Water in the Green Economy in Practice: Towards Rio (Vol.20), 2011.

[16] C. Y. Lin et al., "Habitat quality valuation using InVEST model in Jeju Island," Korean Env. Res., vol. 18, pp. 1-11, May 2015.

[17] M. Terrado et al., "Model development for the assessment of terrestrial and aquatic habitat quality in conservation planning," Science of the Total Environment, vol. 540, pp. 63-70, 2016.

[18] R. Sharp et al., "InVEST user's guide," Stanford University, University of Minnesota, The Nature Conservancy, World Wildlife Fund, 2015.

[19] K. L. Vigerstol and J. E. Aukema, "A comparison of tools for modeling freshwater ecosystem services," Journal of Environmental Management, vol. 92, no. 10, pp. 2403-2409, 2011.

[20] TEEB, "The economics of ecosystems and biodiversity: ecological and economic foundations," London, 2010.

[21] Natural Capital Project, Informing Land-Use Plans in Central Sumatra. INVEST User Guide Release +VERSION, 2012.

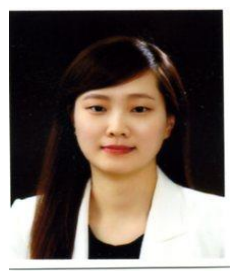

Choi Ji Young is $\mathrm{PhD}$ student in Department of Environmental Science and Engineering, Ewha Womans University, Seoul, South Korea. 